\title{
La vejez problematizada. Imaginarios sociales que toleran lo que otrora era intolerable
}

\author{
ALEJANDRO KLEIN
}

En este trabajo se señala la importancia de la alta experimentación subjetiva en el grupo de los adultos mayores. Se toman como ejemplos tres relatos de vida de adultos mayores de México. Entendemos por "alta experimentación subjetiva" la capacidad de los adultos mayores de modificar sus puntos de vista, escalas de valores, forma de ver el mundo y papeles, y de introducir cambios a la herencia de sus propios abuelos. Esta experimentación, más que basarse en diferencias de clase socioeconómicas, parece mantener hitos transgeneracionales en común. Los adultos mayores revelan inventiva y creatividad, y replantean la vigencia del concepto giddoniano de política emancipatoria, cuya expresión máxima parece ser la confrontación generacional con sus propios abuelos.

PALABRAS CLAVE: envejecimiento, abuelos, políticas emancipatorias, subjetividad, estereotipos sociales

The Problematized Old Age. Social Imaginaries that Tolerate what Would Be Intolerable

This paper seeks to point out the importance of the high subjective experimentation in the group of older adults. We take as examples three stories of life from Mexico. By "high subjective experimentation" one must understand the capacity that aging people are showing to modifying their views, scales of values, way of seeing the world, changing roles, and to introduce modifications to the inheritance that comes from their grandparents. This experimentation, rather than based on socio-economic class difference, seems to maintain cross-generational landmarks in common. These older adults reveal inventiveness and creativity, rethinking the validity of the Giddonian concept of emancipatory politics, whose maximum expression seems to be the generational confrontation with the grandparents themselves. 


\section{Un México envejecido y despreocupado}

a población en México sufrió importantes transformaciones a lo largo del

siglo Xx. Una de las más importantes ha sido la llamada transición demográfica, producto del descenso de la mortalidad a partir de la década de los treinta y el de la fecundidad en los años setenta. Como resultado de estos cambios, la población se ha incrementado, la estructura por edad de la población se ha modificado y la cantidad relativa de adultos mayores ha aumentado, es decir, en México, la población está envejeciendo (Conapo, 2013).

En cifras, en 2010 residían en México poco más de 10 millones $^{1}$ de adultos mayores (INEGI, 2011a; Conapo, 2013). ${ }^{2}$ El salto de los 5 a los 10 milllones ocurrió entre 1990 y 2010 . Se presentó un incremento porcentual de 2.8 respecto al total de la población, esto es, de 6.2 a 9\% de la población total (INEGI, 2014). En México, la esperanza promedio de vida al nacer pasó de 36 años en 1950 a 74 años en 2000. El Consejo Nacional de Polación (Conapo) estima que para 2050 llegará a 80 años. Esta cifra entra en el rango que se proyecta para los países desarrollados. ${ }^{3}$ Los datos indican con claridad que México presenta lo que se denomina "envejecimiento poblacional".

Es importante indicar que, a diferencia de los países desarrollados, en los países no desarrollados el proceso de envejecimiento poblacional sucede a mayor velocidad, con variables que obstaculizan la capacidad de adaptación de la sociedad

$1 \quad$ El dato exacto es 10055379 adultos mayores.

2 En México, el artículo 3 de la Ley de los Derechos de las Personas Adultas Mayores establece que se consideran adultos mayores aquellas personas con 60 años de edad o más. Es importante señalar que en otros países el criterio para delimitar este grupo de edad es de 65 o 70 años o más.

3 En el primer quinquenio del siglo xxI, la esperanza de vida promedio al nacer en los países en desarrollo era de 63.4 años y se proyectaba que llegaría a 73.1 hacia 2050. En los países desarrollados, la esperanza de vida promedio al nacer era de 76 años y se proyectaba su alcance a los 81 años hacia mediados de siglo (Conapo, 2013). 
ante este proceso. Esto ocasiona que a problemas sociales ya crónicos se añadan otros nuevos frente a los cuales el Estado se ve urgido a planificar y hacer efectivas políticas públicas pertinentes (Ham, 1999).

Esta transformación gradual de la estructura etaria de la población altera tanto las demandas sociales como el potencial para generar condiciones de bienestar. Los datos disponibles muestran que en algunas entidades federativas de transición demográfica muy avanzada, como el Estado de México y la Ciudad de México, el envejecimiento de la población es un tema prioritario.

En otras, si bien el envejecimiento aún no es un fenómeno predominante, resulta fundamental que las instituciones comiencen a preparar la infraestructura de servicios propia de una población envejecida (Ham, 2003). En un país con estas características, las políticas públicas en materia de población y desarrollo deberían modificar cada vez más su impacto en función de los niveles y tendencias demográficas (Villagómez, 2009).

De acuerdo con proyecciones del Conapo (2013), para 2020 la población de adultos mayores alcanzará su tasa máxima de crecimiento de 4.2\%, con 14 millones de individuos, es decir, 12.1\% de la población. A partir de ese año, el ritmo de crecimiento demográfico comenzaría a disminuir, hasta alcanzar un crecimiento negativo de $-1.58 \%$, en 2050 , cuando se prevé que habrá cerca de 34 millones de adultos mayores, que representarán 27.7\% de la población total (Villagómez, 2009). El tema no es sólo cuantitativo (Camarena, 2005). Implica también modificaciones cualitativas de todo tipo, no sólo en el plano sociocultural, también en el económico, familiar y productivo (Tuirán, 1999).

Los datos censales de 2010 indican que en el país hay 28.2 millones de hogares y que en uno de cada cuatro, $26.1 \%$, cohabita al menos una persona de 60 años o más (INEGI, 2011a). ${ }^{4}$ En este contexto, es frecuente que los adultos mayores vivan, de manera voluntaria o no, con alguno de sus hijos, lo que constituye, en la mayoría de los casos, una estrategia de supervivencia y bienestar, sobre todo en las etapas más avanzadas del envejecimiento. ${ }^{5}$

Por otro lado, como ha señalado Ham (1999; 2003), esta presencia de lo familiar obedece también a un reclamo de que los parientes se ocupen de funciones que se supone que le corresponden al Estado. Se espera que la familia solucione lo que éste y la sociedad no pueden. Lo que sucede en realidad, de acuerdo con los datos que aquí se presentan, es que no sólo la familia es incapaz de resolver lo que se ha de resolver en el ámbito gubernamental, sino que, por lo general, se encuentra sometida a exigencias que la hacen vulnerable e incrementan su ambivalencia ante el adulto mayor.

A diferencia de lo que ocurre en sociedades en las que el sistema de pensiones está muy extendido, en México pocos adultos mayores disponen de pensiones o capital acumulado. En 2001, sólo 18\% de los adultos mayores que había trabajado en algún momento de su vida recibía pensión. La precariedad de esta cifra puede deberse, en parte, a la alta frecuencia de la informalidad en el mercado laboral (Rabell y Murillo, 2013). Por otro lado, “cerca del $50 \%$ de la población mexicana con 65 años o más no tiene derecho a sistemas de salud" (Mancinas y Garay, 2013: 396).

$4 \quad$ Gran parte de los adultos mayores pertenece a un hogar familiar: $43.4 \%$ cohabita en un hogar nuclear y $44.5 \%$ en un hogar ampliado y compuesto. La estructura de parentesco en los hogares nucleares indica que dos de cada tres, 64.2\%, son jefes del hogar, mientras que $34.6 \%$ son cónyuges; sólo $1.2 \%$ son hijos. En los hogares ampliados y compuestos la configuración del parentesco cambia y surgen otras figuras asociadas a las personas en edad avanzada, como los abuelos o los suegros, entre otras (INEGI, 2011a).

$5 \quad$ Uno de cada dos adultos mayores, 51.7\%, que cohabita en un hogar ampliado o compuesto es considerado jefe del hogar; $18.9 \%$ es cónyuge del jefe; $13.5 \%$ es madre o padre del jefe, $6.1 \%$ es suegro; $9.1 \%$ tiene otro parentesco y $0.7 \%$ no tiene lazos sanguíneos con el jefe del hogar (INEGI, 2011b). 
Sin embargo, el problema central radica en la relación entre la edad y las condiciones de pobreza o vulnerabilidad. En 2012, de acuerdo con el Consejo Nacional de Evaluación de la Política de Desarrollo Social (Coneval, 2012), 43.2\% de la población de 60 años o más se encontraba en condiciones de pobreza multidimensional y siete de cada diez adultos mayores, 72\%, padecían vulnerabilidad social, lo que implica que presentaban, por lo menos, alguna de las siguientes carencias sociales: rezago educativo, falta de acceso a los servicios de salud, falta de acceso a la seguridad social, deficiencias en la calidad y los espacios de la vivienda y en los servicios básicos, y falta de acceso a la alimentación.

$\mathrm{Al}$ desglosar estos datos, se revela que uno de cada dos adultos mayores, $49.4 \%$, es vulnerable por ingresos, es decir, su ingreso es inferior o igual a la línea de bienestar. Este dato se compone de 43.2\% de adultos mayores que también son vulnerables por carencias sociales y $6.2 \%$ que es vulnerable por ingresos y no presenta carencias sociales. Destaca que sólo $21.8 \%$ de los adultos mayores se considera "no pobres multidimensionales ni vulnerables por ingresos o por carencias sociales y de ingresos" (Coneval, 2012: 14). Datos más recientes (SNIEG, 2017; Conapo, 2014) no muestran un cambio sustantivo en las tendencias, por el contrario, éstas parecen agravarse con el paso del tiempo.

Los efectos que ha tenido en estos procesos el Seguro Popular de la Comisión Nacional de Protección Social en Salud merecen un estudio aparte. Los datos oficiales no coinciden con los que presentamos en este trabajo. ${ }^{6}$ La cobertura de salud y el combate a la pobreza de los que se habla en tono triunfalista no se verifican de manera empírica. En general, estas instituciones ofrecen una serie de servicios deficitarios que no consideran al otro como un ciudadano con derechos, pues el Estado actúa como el dador de una limosna que hay que agradecer (Klein, 2016).

Esto es fundamental: la desciudadanización imperante ha dado lugar al desarrollo de políticas públicas y medidas de intervención social que no cumplen sus objetivos a cabalidad y reproducen lo que se supone que intentan combatir. Ello revela un ciclo crónico de miseria, desprotección y desvalimiento (Klein y Ávila-Eggleton, 2015). En un trabajo con Marcela Ávila-Eggleton (2015), de carácer más politológico, mostramos que desde las últimas elecciones presidenciales en México, el grupo de la tercera edad se ha transformado en un actor social decisivo para las transformaciones sociales y políticas, y que esto puede aprovecharse en su beneficio y en el de todo el colectivo social.

En la presente investigación, por medio de tres historias de vida, veremos cómo, a pesar de las adversidades socioeconómicas, el grupo de la tercera edad está pasando por un campo de alta experimentación subjetiva, avalado, entre otros factores, por un imaginario social más tolerante y permisivo.

El andamiaje teórico desde el que serán observadas las historias es el análisis de fragmentos o relatos de vida, a partir de entrevistas a profundidad con un enfoque biográfico. El objetivo es indagar cómo se vive hoy la ancianidad y la "abuelidad" en distintos estratos sociales. Se intentará mantener una distancia operativa que permita comprender actitudes, tendencias y cambios.

\section{El caso de José: el comienzo de la experimentación subjetiva}

José tiene 68 años de edad y los aparenta. Su rostro fatigado y los callos de sus manos muestran que ha trabajado toda su vida en varios oficios: albañil, carpintero, obrero de la construcción. Está orgulloso de eso. Dice que toda su vida ha sido de sacrificios, pero que no por eso ha dejado de ahorrar para

$6 \quad$ Véanse Comisión Nacional de Protección Social en Salud (s. f.) y Secretaría de Salud (2005). 


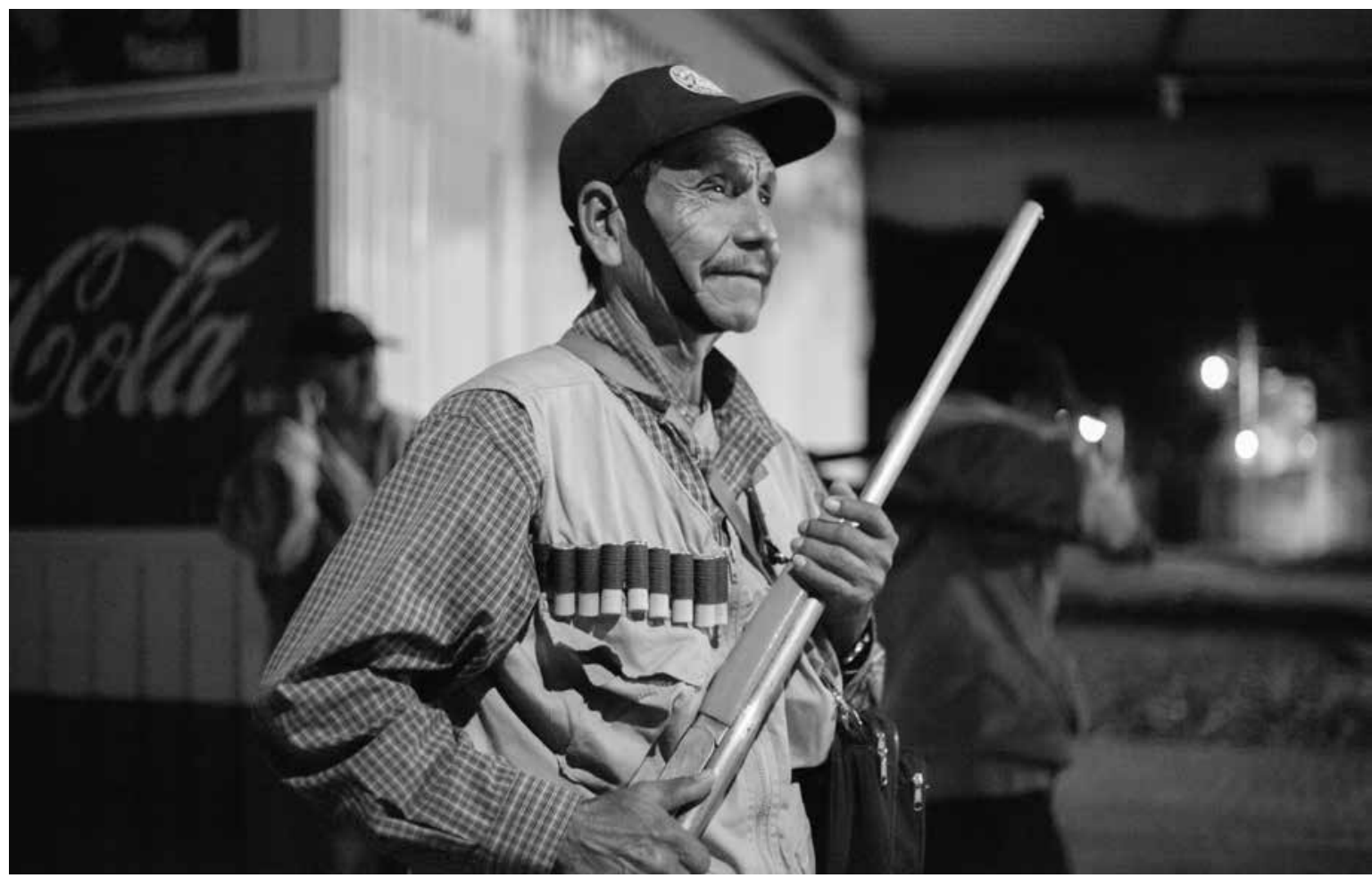

Prometeo LuCERo Policías comunitarios de Huamuxtitlán, agrupados en el Concejo Ciudadano, se organizan para hacer rondas por la noche, febrero de 2013.

comprar su "casita". Dice que si algo le quiere dejar a sus nietos "es el ejemplo de que con honradez y trabajo las cosas se pueden hacer, tener sus cositas. Quiero ser el ejemplo de mis nietos". ${ }^{7}$

Cada una de sus dos hijas tiene dos hijos. Dice que los cuatro nietos le aparecieron de repente, que no se lo esperaba, tampoco su esposa, y que se han ido a vivir a su casa con sus hijos y yernos: "no tienen dónde ir, y bueno, me puse a agrandar la casa. Pero en cómo educan a sus hijos no me meto. Que hagan lo que les parezca mejor. Sin embargo, mis abuelos sí nos educaban, pero yo prefiero que no. Así es mejor. Ya fui papá, serlo de vuelta me cansa".

José no se ha jubilado ni piensa hacerlo: "me moriré trabajando. Tengo mucho para hacer. Trabajar me hace sentirme vivo y fuerte. Así me gusta a mí [...]. Mis abuelos no, ellos se jubilaron, pero conocí a sólo dos de ellos, los otros murieron cuando yo era pequeño".

Dice que le gusta cantarle a sus nietos, cosa que sus abuelos también hacían con él, aunque insiste en que él es un abuelo lleno de salud, mientras que los suyos eran muy viejos. Sin notarlo, expresa que admiraba a sus abuelos, pero que no por eso será como ellos: "yo no le pego jamás a mis nietos. Eso lo hacen mis yernos. A mí mis abuelos [me] castigaban, pero eso no me gusta. Mi esposa tampoco lo hace. Por eso mis nietos me quieren tanto". Que los nietos no le tengan miedo o terror es fundamental para él,

Testimonios extraídos de las entrevistas con José, León, Guanajuato, de julio a noviembre de 2016. 
pero el respeto también: "eso sí, que me respeten como yo respetaba a mis abuelos".

A partir de lo que nos cuenta, percibimos que la familia está fuertemente territorializada, aunque vive en la misma casa. Es decir, los abuelos sienten que hay un terreno que es de los padres y que no quieren invadir de ninguna manera. De la misma manera, no quieren que los padres invadan lo que ellos consideran sus consignas o privilegios con sus nietos. Una hipótesis, unida a la anterior, es que de ninguna manera quieren que se les confunda con los padres, es decir, no quieren que haya similitud, y José hace todo lo posible, según nos cuenta, para que a los nietos esto les quede bien claro.

Otro aspecto interesante que encontramos es que José no le teme al ridículo: "si tengo que jugar con mis nietos me gusta mucho. Jugamos a los piratas, los payasos, nos tiramos al piso. Yo les hago caras y se ríen y eso me pone muy contento". Es decir, hace cosas que sus propios abuelos jamás hubieran hecho con él. José quiere jugar, en su comportamiento predomina lo lúdico y disfruta de esa vida, así es feliz.

Algo nuevo que también encontramos tiene que ver con la dimensión del sacrificio, que está desapareciendo en José, aunque siempre la asoció a su abuelo: “yo, por mis nietos, hago lo que puedo. $\mathrm{Ni}$ más ni menos. Mi esposa igual. A veces los cuidamos, otras no. Le digo a mis hijas que hago lo que puedo, ya bastante con agrandar la casa, ¿no le parece? Ya fue mucho trabajo para mí".

José siente que no se tiene que sacrificar o ser altruista con sus nietos, sino que despliega una evaluación muy realista de lo que hace y lo que no, de lo que puede y no puede hacer con ellos. Sabe que no puede salir con sus nietos al cine o invitarlos a comer. Pero sí puede, por ejemplo, reunir a la familia los domingos, que es un día muy importante, porque toda la familia come junta: "los domingos son sagrados, mi señora cocina y todos deben venir, es una tradición de toda la familia, lo hemos hecho siempre y siempre con mucho sacrificio y amor".
Respecto al género, en este grupo, del cual José forma parte, aunque todos son abuelos hombres, se sienten con los mismos derechos y las mismas capacidades y habilidades que las abuelas. Es decir, no sienten que las abuelas son más abuelas y los abuelos menos abuelos. José se siente en un plano de similitud con su esposa: "a mí me gusta ser abuelo, me gusta jugar con ellos, llevármelos a trabajar para que vean que el trabajo es muy importante. Que no salgan flojos [holgazanes]". De cualquier manera, trata de manera diferente a su nieta. Dice: "es mujer, las mujeres son más delicadas, ¿no?”.

Sin embargo, hay un punto que nos impactó. Cuando le preguntamos si le gustaba vivir en familia, dijo: "no, la verdad no. Me gustaría que me visitaran, pero no tenerlos en la casa todo el día. A mi esposa y a mí nos gusta estar solos y nos la pasamos bien". Hay aquí un claro indicio de comienzo de cambio subjetivo que se une al hecho de que, aunque son abuelos, no por eso se sienten viejos:

Yo me sigo levantando a las 6:00 de la mañana, desde
niño lo hice. Me levanto con el sol y me hace sentir
aún joven y lleno de vigor. Y con mi esposa, todavía,
a veces... La cabeza me funciona muy bien. No estoy
senil ni nada. Recuerdo el nombre de mis amigos,
nietos e hijas y los de mis papás y abuelos y casi todas
las fechas de mi cumpleaños. No, señor, no soy viejo.
Y a veces voy con mi señora a la iglesia, aunque no
creo mucho en eso de rezar, pero a ella le gusta que
vaya. Pero no crea que me pienso morir, al contrario.

Lo que más le disgusta es que sus nietos "hayan venido así, de repente", es decir, José se refiere a que no hubo planificación familiar. En su contexto socioeconómico humilde, la mujer "simplemente" queda embarazada y de manera indefectible José se siente un sostén familiar: "les doy todo lo que puedo pero sin exagerar [...]. Soy estricto, pero no como mis abuelos, que eran muy enojones. También me divierto y la paso bien con mis nietos". 
Para José, ser abuelo es ser un abuelo amable y lo integra sin mayor problema a su vida cotidiana. Al mismo tiempo, aparece como un guardián muy serio y convencido de determinados modelos sociales, en especial el del "obrero digno" (Klein, 2013); valora trabajar, ahorrar, ser responsable. Le dice al nieto: "te doy dinero, pero no lo gastes así nomás, tienes que gastarlo de a poquito". Le da ese dinero de preferencia los domingos, o sea, el día del ritual de la comida en familia.

Como vemos, José disfruta ser abuelo: "no lo cambio por nada [...]. Mis nietos me dicen cosas lindas y a veces tienen razón. Me dicen que no tome Coca-Cola, que no coma tantos tacos... [se emociona]". Son parte de su experiencia y enriquecimiento de vida y siente algo muy conmovedor: que los nietos le ayudan a transformarse en mejor ser humano. José siente que ayuda y hace cosas por sus nietos, pero también que ellos hacen cosas por él.

\section{El caso de Enrique: cambiar ya es posible}

Enrique tiene 69 años de edad y ha comenzado los trámites de su jubilación. Ocupa un cargo gerencial en una industria de zapatos, típica de la ciudad de León: "ya me tengo que jubilar, pero no quiero. Aún puedo hacer cosas por los más jóvenes, enseñarles cosas de la fábrica. Pero me han ofrecido una compensación si me voy y me viene muy bien para viajar con $\mathrm{N}$ [su actual esposa]". ${ }^{8}$

Enrique pertenece a un contexto de clase media y mandos intermedios, es viudo y se ha vuelto a casar. Sus planes son viajar y divertirse mientras tenga salud. Tiene tres nietos, dos de su hijo y otro de su hija. Al igual que en el caso anterior, no piensa en morir, no le pasa por la cabeza algo así. Es literalmente impensable.

Está orgulloso de que su hija haya esperado a titularse para ser mamá. Para Enrique, una familia es una familia planificada, en la que cada cosa tiene su lugar y tiempo. Para él, ser abuelo es parte de una biografía y un ciclo de vida. Primero se es padre, después toca ser abuelo, lo que está cargado de significación: "yo esperaba ser abuelo, sabía que mis hijos tendrían a mis nietos en el momento justo, ni antes ni después. Cuando nacieron, me puse feliz. Fue y es algo muy importante en mi vida. Mi nueva pareja no tiene nietos, adoptó los míos". Lo que Enrique transmite como concepto fundamental es el sentido de gratificación. Ser abuelo es gratificante y él siente que gratifica a sus nietos.

Enrique logra un equilibrio entre las actividades del trabajo y las de la familia. No quiere ser abuelo de tiempo completo ni trabajador de tiempo completo. En su modalidad subjetiva logra hacer un balance entre ambos aspectos. Cuando le preguntamos de dónde sacó el modelo para ser abuelo, dice: "de mis papás. Aprendí muchas cosas de ellos y las aplico a mis nietos, como antes a mis hijos". Aquí no encontramos que hubiera una brecha o una discontinuidad generacional muy pronunciada, como se verá en los otros dos casos. Hay mayor continuidad generacional y parece haber procesos de transmisión generacional más legitimados de los abuelos a los hijos y a los nietos.

Enrique destaca que ha tenido una buena relación con sus padres y siente que éstos lo han apoyado mucho. De nuevo aparece un límite: él se dedica a cuidar, no a educar.

Yo a mis nietos los saco a pasear o al cine, pero no los educo, ésas son cosas de sus papás. Mis nietos me gratifican, son un apoyo en mi vida, me gusta verlos crecer y hacerse grandes. Tengo debilidad con ellos, a veces cuando los padres se ponen muy gruñones trato de intervenir.

Testimonios extraídos de las entrevistas con Enrique, León, Guanajuato, de julio a noviembre de 2016. 


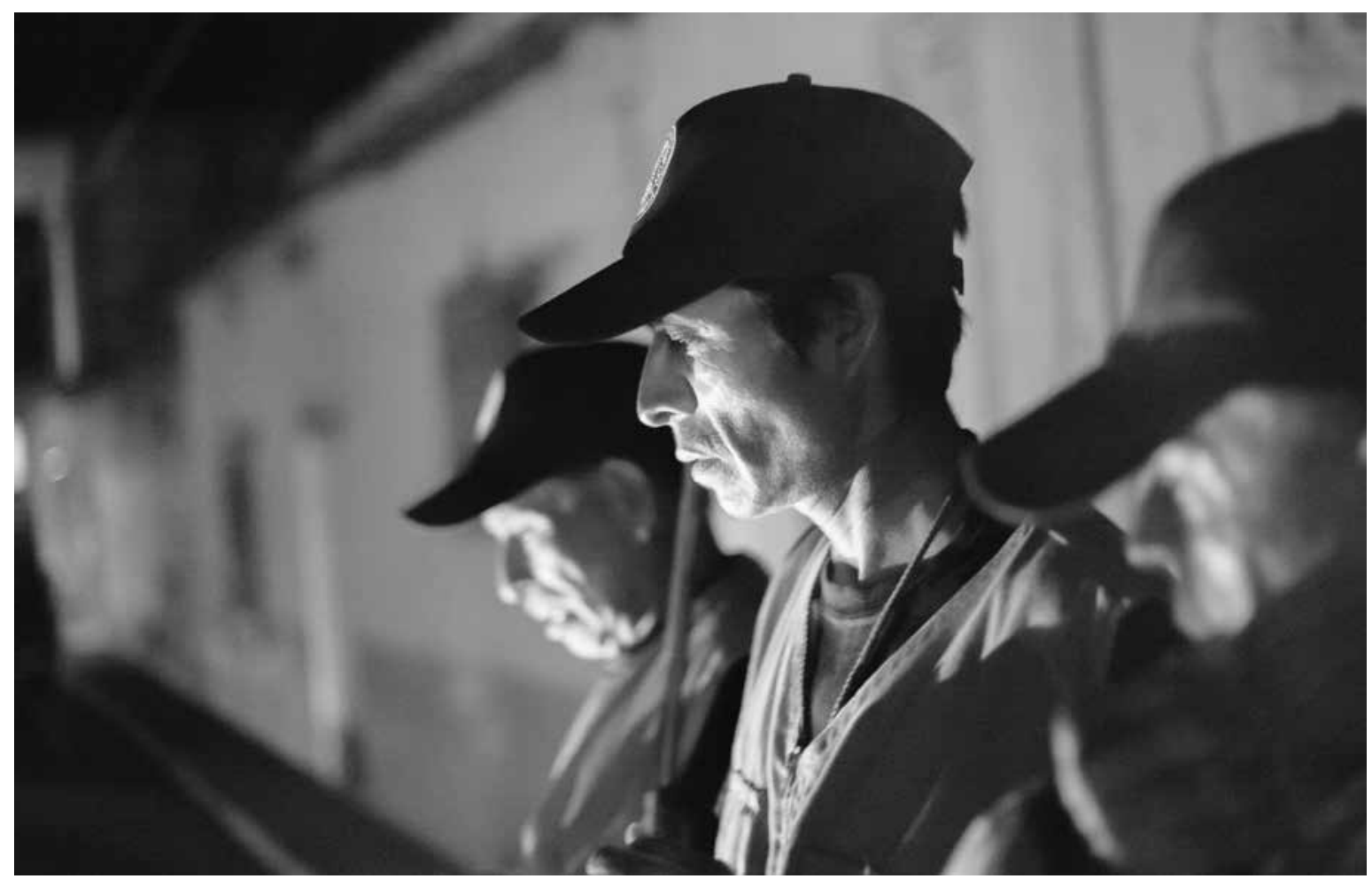

Prometeo Lucero • Policías comunitarios de Huamuxtitlán, febrero de 2013.

Esto es algo nuevo, que no aparece en las demás historias de vida. A pesar de que respeta la territorialización de los padres, Enrique siente que a veces puede intervenir cuando los padres están muy enojados, entonces trata de apaciguar las cosas, que haya paz, que haya un armisticio. Por otra parte, lo que predomina en el vínculo con sus nietos es la adaptación mutua: "nos ponemos de acuerdo en los horarios, en la película que vamos a ver, en la comida y nos entendemos muy bien".

Enrique se adapta a cómo son los nietos y espera que los nietos se adapten a cómo es él. Otra vez aparece lo lúdico en primer lugar: compartir tiempo juntos, disfrutarlos, convivir en una relación simétrica. Se destaca su disposición a acompañarlos: "mi nieto tiene problemas con las matemáticas y yo me hago tiempo para ayudarle en todo lo que puedo".
Aunque Enrique es muy indulgente en general, se atreve más que otros a criticar a sus abuelos: "eran muy severos, había que hacer caso o venía algún castigo, a veces una paliza”. Esto permite afirmar que él jamás le ha pegado a sus nietos. La época de los castigos corporales ha quedado atrás. Sin embargo, Enrique no puede disimular que tiene muchas expectativas respecto a sus nietos: "quiero que lleguen a ser gente importante, que destaquen, gerentes de algo, ¿por qué no? Se les está dando una excelente educación".

Por último, encontramos un rasgo esencial, a diferencia de los nietos de José, los de Enrique viven en su propia casa. Para estos mandos intermedios, un abuelo ideal es el que puede hacer una inversión económica, además de emocional, social y de tiempo con sus nietos, mientras que en una franja de ingresos humildes es mucho más importante el apoyo moral que la inversión económica. 


\section{El caso de Juan: la franca experimentación subjetiva}

Juan tiene 70 años de edad, pero no los aparenta. A lo sumo podríamos pensar que tiene 55. Vive en la ciudad de Querétaro. Pertenece a la clase media alta, sin apremios económicos o sociales. Incluso en su aspecto personal, Juan es francamente rupturista: "sé que no me visto como viejo. No quiero parecer viejo. No me siento viejo. Me gusta ser abuelo, pero no un hombre débil o que necesita ayuda... Me gusta estar con mis nietos por el gusto de estar, nomás. No necesito que me ayuden en mi vida". ${ }^{9}$

$\mathrm{Al}$ preguntarle sobre sus rutinas, dice:

Voy al gimnasio. No tanto como querría, pero voy al menos tres veces a la semana. No como cosas grasosas. Mi esposa y yo somos cuidadosos en lo que comemos. Preferimos el agua a la Coca-Cola. Hace 30 años que estamos juntos. No le he sido infiel. Es cierto que fumo de vez en cuando. Ese vicio no me lo puedo sacar. Hace poco me jubilé de profesor en la universidad, pero mi vida no se termina. Sigo haciendo cosas, manualidades o leo. Veo a mis amigos, pero lamentablemente algunos tienen Alzheimer o demencia. No los voy a ver. Yo no soy viejo como ellos. Quiero ser joven y tener vigor.

No quiere hablar de su sexualidad por un sentido de pudor que respetamos, pero su cara se ilumina de orgullo cuando dice: “ $¿$ sabe? Yo no voy al parque a darle miguitas a las palomitas. Nada de eso. Yo no me aburro. Me jubilé porque tenía que jubilarme, si no, seguía de largo nomás". Cuando le preguntamos sobre sus abuelos, dice:

Mis abuelos eran buena gente. No recuerdo que nos pegaran. Tendría que preguntar a mis hermanos [dos menores que él]. Pero eso sí, había que respetarlos. Tratarlos de "usted". Mis nietos me hablan de otra manera. Me tutean. Pero me gusta.
Yo entiendo que antes las cosas eran así. Pero ahora ya no. Tenemos confianza, nos hablamos las cosas. Mis nietos me preguntan cosas que yo jamás me hubiera atrevido con mis abuelos. Y me cuentan cosas de su vida íntima que me chocan un poco, pero me pone orgulloso que me las cuenten. Para eso está un abuelo.

Juan tiene dos hijos y cada uno tiene un hijo a su vez. Cuándo le preguntamos cómo educa a sus nietos, piensa largo rato antes de decir: "¿educarlos? Ah, no sé. Tengo que pensarlo. ¿Educarlos? No, creo que no. Eso es de sus padres. Yo no me meto. Conmigo que salgan, vamos al cine, a comer, a pasear. Pero no quiero educarlos, para eso están mis hijos". Agrega: "yo respetaba y respeto a mis abuelos. Pero yo soy otro abuelo, no sé si mejor o peor. Usted dígame. Pero lo más importante para mí es el cariño y la confianza".

\section{Análisis de las entrevistas con José, Enrique y Juan}

La política de tanteo y experimentación subjetiva es transversal en las tres historias de vida. No es un factor socioeconómico sino etario-generacional que unifica a los tres entrevistados más allá de sus contextos de vida. En mayor o menor grado, los tres están experimentando cómo ser abuelos. En general, los tres van construyendo, por ensayo y error, cómo serlo.

Aparece un detalle interesante: se desligan en definitiva del papel de la educación. Quienes educan son los padres, ellos no. Ellos la pasan bien con los nietos, los socializan en el mejor de los casos. No les interesa educar, pues entienden que eso le toca a

9

Testimonios extraidos de las entrevistas con Juan, León, Guanajuato, de julio a noviembre de 2016. 
los padres. Lo que sí hacen es socializar a partir del ejemplo de ellos mismos y de lo afectivo. José socializa con el esfuerzo, el ahorro, el tener que ser trabajador, responsable, obediente y precavido. Enrique lo hace con su deseo de juventud. Juan con el ideal de autonomía e independencia.

Otro dato importante, también transgeneracional, es la descalificación y deslegitimación del castigo corporal. Dicen que de ninguna manera golpean a sus nietos. Ellos mismos, insistimos, no se ven en un papel represor, pues hablan mucho más con sus nietos de lo que sus propios abuelos, décadas atrás, hablaban con ellos.

Lo más importante es, en primer lugar, el diálogo, hablar con los nietos. Tal vez la palabra clave para este grupo es que estar con los nietos es disfrutar a los nietos. Además, hacen cosas juntos, que sólo son posibles en el campo de experimentación de sus subjetividades, y por ende, de sus relaciones: jugar, pasear, mirar la televisión, salir de aventuras, usar la computadora. El tema de la computadora es relevante: comparten el dispositivo y sus nietos les enseñan cómo usarlo, los programas y las posibilidades de las aplicaciones de internet, como Google, Facebook, Twitter.

Es probable que estos abuelos hayan modificado su papel y función de manera cualitativa antes que los padres modifiquen los suyos. Es decir, podría pensarse que su campo de experimentación subjetiva es mayor que el de sus propios hijos. Estos abuelos son mucho más flexibles en su capacidad de cambio que los padres de sus nietos, quienes aparecen más rígidos y tradicionales, más adheridos a determinadas formas de ser padres. Creemos que se puede afirmar que estos abuelos son mucho más perceptivos, sensibles y abiertos a los cambios culturales.

Aunado a lo anterior, el mensaje de que pueden dar dinero, apoyo moral y socialización aparece con claridad, pero no sienten que deban transmitir una enseñanza o educación. Esto señala una diferencia radical con los abuelos de estos abuelos, porque de aquéllos se esperaba que educaran y fueran severos, porque se pensaba que ésa era la forma de educar a la gente. Los tres denuncian que se los golpeaba ante situaciones que no podían comprender del todo. Hay, probablemente, una crítica muy velada, sutil y respetuosa a sus propios abuelos, pues en el fondo ellos se sienten mejores abuelos. Esto es lo que denominamos "confrontación generacionaltransgeneracional".

Anuncian, por ende, que el modelo del abuelo como patriarca está agotado. La idea del abuelo todopoderoso que manda y al que todos obedecen está en una etapa de fragilidad. En ese sentido, la expresión de emociones ya no entra en conflicto con la figura de la masculinidad. Estos abuelos hombres aceptan lo afectivo: pueden llorar y sonreír, no tienen que ser severos todo el tiempo, con una actitud seria y estoica.

Nuestra hipótesis es que, así como hay una ruptura con sus abuelos, se retoma un nuevo contrato generacional con los nietos. Parte de ese contrato generacional parece decir: "estoy pendiente para mis nietos, mis nietos estarán pendientes para mí”, dentro de un campo de gran experimentación subjetiva.

\section{Los sistemas de fiabilidad}

Giddens (1997a; 1997b) plantea una reflexión acerca de lo que denomina "sistemas expertos" y la manera en que éstos generan condiciones de confianza básica en la sociedad. Estos sistemas de confianza básica sustentan la idea de previsibilidad, y en ese sentido, son indisociables del concepto de anticipación (Aulagnier,1991; Castoriadis-Aulagnier, 1975) y rutinización (Giddens, 1997a; 1999):

Los sistemas en los cuales los conocimientos expertos están integrados influyen sobre muchos aspectos de lo que hacemos de manera regular. Simplemente al sentarme en mi casa yo estoy implicado en un sistema experto, o en una serie de tales sistemas en 
los que pongo mi confianza. No siento particular temor en subir las escaleras de la casa incluso a sabiendas de que en principio podría colapsarse la estructura. Sé muy poco de los códigos de conocimiento utilizados por el arquitecto y el constructor en el diseño y construcción de la casa. No obstante, tengo fe en lo que han hecho. Mi fe no es tanto en ellos, aunque tenga que confiar en sus competencias, sino en la autenticidad del conocimiento experto que han aplicado (Giddens, 1999: 37).

La palabra clave es confianza, relacionada con el sentimiento de autenticidad, estabilidad y buena fe de la o las instituciones encargadas de sostener estos sistemas expertos, lo que a su vez debe relacionarse con una modernidad asentada en principios racionales (Habermas, 2008).

Es importante tener en cuenta que el modelo social giddoniano supone la necesidad del funcionamiento permanente de sistemas expertos que hagan las veces de metaencuadre, imprescindible en los sistemas de confianza. Las personas toman decisiones en forma de riesgos controlados cuando esta confianza se muestra válida y en funcionamiento. Es una forma, si se quiere, de legitimidad de los aspectos vitales que hacen a la sociedad: cuidado, protección, resguardo, elementos resumibles en lo que Foucault presenta como biopolítica (1984; 2004a; 2004b).

Esto se suma a la idea de que la persona, en tanto ciudadana, tiene derechos incuestionables y la posibilidad de tomar decisiones que determinarán el rumbo de su vida y su entorno social dentro de un proceso de negociación permanente (Klein, 2006; Kaës, 1996). Hay que añadir que si se establece un futuro es para mejorar, tanto desde las políticas de cambio como desde la experimentación subjetiva.

A partir de lo anterior, emitimos la hipótesis de que si hay un grupo social en el que se vive el riesgo y la oportunidad, como convencimiento de la oportunidad de poseer un futuro y ser mejor, éste es el de los adultos mayores. Tal vez los planteamientos de la teoría de Giddens sobre los sistemas de seguridad no se observan con claridad en las narraciones que aquí se presentaron, pues éstas más bien se perciben como formas de adaptación de los ancianos asumidas por voluntad. Queremos insistir en que estas determinaciones voluntarias, unidas a una mejor calidad de vida y a los avances médico-tecnológicos, deberían enriquecerse con un clima cultural propicio, de acompañamiento, en forma de sistemas expertos que se redefinan de manera permanente para sustentar la capacidad de alta experimentación subjetiva de los adultos mayores.

En este punto se unen las elecciones negociadas de la vida — vocacional, matrimonial, de divorcio, de vínculos con los nietos y otros-, entendidas como oportunidades de mejora (Giddens, 1999), y pasan a tener relevancia más clara los sistemas expertos que funcionan como organizadores del entorno material y social en el que vivimos (Giddens, 1997b), como expresión del sentimiento de confianza, seguridad y resguardo que provee la estructura social y cultural. Una de sus máximas expresiones es la tolerancia a la capacidad de confrontación generacional-transgeneracional de estos abuelos con sus propios abuelos y la constitución de un nuevo contrato generacional con sus nietos.

\section{Empoderamiento del adulto mayor: un enigma a dilucidar}

Los aspectos señalados en el primer apartado de este trabajo podrían dar la idea de que el adulto mayor está expuesto a un alto grado de vulnerabilidad. Sin embargo, otros datos invitan a problematizar esta cuestión (Neugarten, 1999; Neugarten y Weinstein, 1964). En efecto, la figura de lo que antes se denominaba "viejo" o "anciano", hoy "adulto mayor" o "tardío", condensa reflexiones y dilemas que se plantean en los cambios culturales y sociales actuales, que están en revisión y renovación (Cumming y Henry, 1961; Cole, 1997). 
Si retomamos al grupo "rupturista" de los viejos, es posible estimar que su escándalo actual radica en que ya no aceptan ser viejos. No aceptan el mandato generacional de la decrepitud, por así decirlo. Hacen una verdadera confrontación transgeneracional, cuyos resultados son imprevisibles. Se ha hablado de una revolución feminista (Giddens, 1997a; 1999), habría que plantearse ahora si estamos ante una "revolución" gerontológica. Al igual que la mujer en el siglo XX, estos viejos-no viejos están tomando un protagonismo impredecible en la ciudadanía, en las políticas públicas y en la reformulación de vínculos y procesos familiares, entre otros.

Por otro lado, no es posible desconocer que la gerontología sigue siendo un campo con predominio de las ciencias médicas y biológicas (Barros y Castro, 2002), desde el cual el problema de la vejez se transforma en cómo detener el proceso de envejecimiento con las tecnologías modernas o cómo desterrar la muerte mediante el complejo médicofarmacológico. Ambas estrategias, entre otras, se desenvuelven dentro de una prolongación de longevidad ad infinitum, una especie de promesa matusalénica hecha realidad (Ariès y Duby, 1990). En este sentido, no hay aquí "revolución" sino "manipulación" de subjetividad, deseos y estrategias de vida en la lógica del consumo y el engaño, de quimeras que se multiplican a sí mismas.

Los adultos mayores ven delante de sí una segunda, tercera o cuarta oportunidad en términos de proyectos, es decir, ven vida y no muerte. Quizá podría hablarse de un fortalecimiento de las estéticas corporales no decrépitas (Klein, 2002). Los abuelos de hoy — no todos, pero sí muchos- no

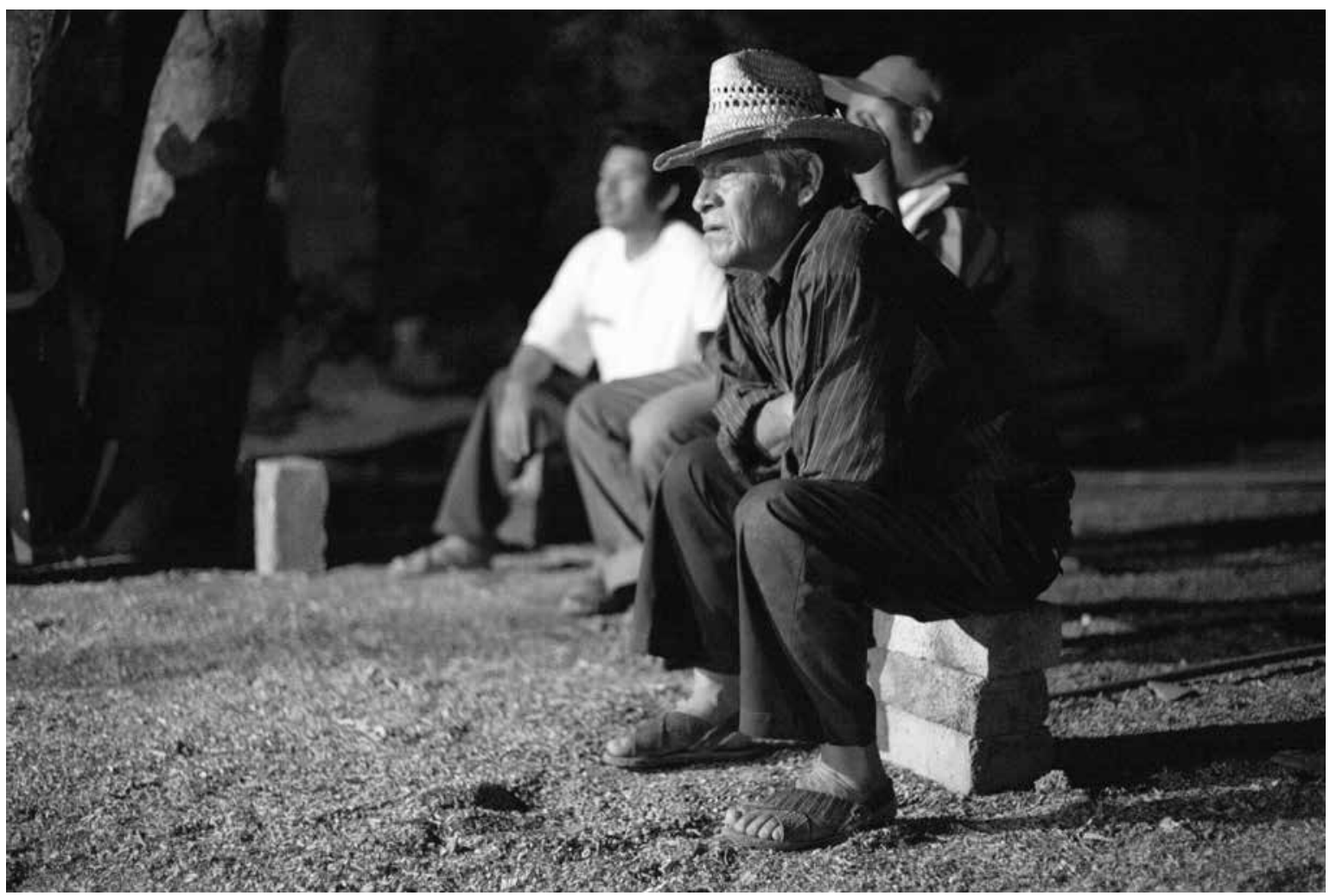

PRometeo Lucero - Concejo Ciudadano de Huamuxtitlán, Montaña de Guerrero, discute temas relacionados con la seguridad, febrero de 2013. 
quieren ser abuelos o viejos según los modelos heredados. No transmiten esos modelos porque no quieren reproducirlos. Hay un efecto de detención de la transmisión intergeneracional, tal vez inédita en la historia de las mentalidades y las culturas.

Por eso, una función de subjetivación adscrita como inherente a la adolescencia - la confrontación transgeneracional (Klein, 2003; 2004) - es ahora parte de la subjetividad de estos abuelos posadultos, entendida como oportunidad de mejora en medio de una crisis biográfica (Giddens, 1997a).

A la idea de lo biográfico se une también la idea —organizadora - de lo etario, como un orden que impone una sucesión preestablecida. El adulto es precedido por el adolescente y sucedido por la vejez. Esta construcción biográfica etaria, sin embargo, parece encontrarse en un franco proceso de cambio, sustituida por otro proceso biográfico de tipo transetario, en el que las edades se mezclan o se vuelven indiscernibles, ambiguas o innecesarias. Ricardo Iacub (2006) utiliza el término transetario en una cultura posmoderna en la que se intenta mantener el cuerpo sin envejecer, inserto en una perspectiva tecnológica que anula lo temporal, para dar lugar a lo que podría denominarse ucrónico. La identidad ya no se define por la edad y podría entenderse que tampoco por la primacía de un cuerpo rejuvenecido.

Existe una línea de análisis de subjetividad $-\mathrm{y}$ de la vejez - desde la cual se rescatan reflexiones valiosas, como las de Regina Duarte de Barros y Adriana Miranda de Castro (2002), quienes sitúan de manera atinada cómo se gesta la figura social de un "nuevo viejo", de acuerdo con prácticas capitalistas relacionadas con un discurso médico en el que se construye...

un "nuevo viejo", un viejo que debe mantenerse apartado del envejecimiento por medio de la práctica de actividades físicas elementales, que le garantizarán el mantenimiento de sus capacidades funcionales, y en última instancia, de su juventud
[...]. Tomar al "nuevo viejo" como identidad fija, indicaría, en nuestra perspectiva, acciones estigmatizadoras, tanto como aquellas que antes se aplicaban [...] al "viejo" (Barros y Castro, 2002: 120-123). ${ }^{10}$

Barros y Castro lo explican así: "consideramos necesario destacar que tales vectores [...] se articulan en la composición del tejido sociopolítico contemporáneo, que expresa un modo dominante de subjetivación" (2002: 122). ${ }^{11}$

De esta manera, puede suponerse que los "nuevos viejos", si bien se relacionan con un entrelazado socioeconómico que responde a varias estigmatizaciones, también se articulan a construcciones de subjetividad nuevas y alternativas, en las que rescatan el sentido de autonomía y elección, al incidir en la capacidad y empoderamiento de un debate dentro de modalidades subjetivas emergentes en las que pueden, además, negociar y apoderarse de espacios y prácticas de libertad (Foucault, 1984).

En el grupo etario de la tercera edad se robustece lo que Giddens denomina "políticas emancipatorias", encaradas no tanto desde la capacidad de independencia, sino desde "el esfuerzo por liberarse de las ataduras del pasado, permitiendo así una actitud transformadora frente al futuro y el objetivo de superar el dominio ilegítimo de algunos individuos o grupos sobre otros" (1997a: 267). Creemos que, en efecto, esta actitud transformadora no ha sido vulnerada por las condiciones precarias en las que

10

'Um 'novo velho', um velho que deve se manter afastado do envelhecimento a través da prática de atividades físicas ementais, as quais Ihe garantiriam a manutenção de suas capacidades funcionais e, em última análise, de sua juventude [...]. Tomar o 'novo velho' como identidade fixada indicaria, a nosso ver, ações estigmatizadoras, tanto quanto aquelas que anteriormente estavam postas [...] sobre o 'velho'" [la traducción es mía].

11 "Consideramos, entretanto, necessário destacar que tais vetores...estão articulados na composição do tecido sóciopolitico contemporâneo que expressa um modo dominante de subjetivação" [la traducción es mía]. 
viven muchos grupos de tercera edad, pues al mismo tiempo se han beneficiado de un imaginario social que los revalora y reposiciona.

\section{Conclusiones}

Por diversos factores, los adultos mayores parecen poseer un presente que contiene también la expectativa de un futuro. Los estudios a los que nos hemos referido indican una resiliencia que se apoya en estrategias de supervivencia emancipatorias en verdad eficaces.

Creemos que un factor fundamental es la posibilidad de consolidar distintas redes (Arias, 2013). Así, es posible considerar la manera en que algunas prácticas sociales y grupales decisivas habilitan un sentimiento de autoconfianza, de expansión de la identidad y de reconocimiento del otro desde un lugar solidario (Czernikowski, 2003), como una forma de actualización de imaginarios y vínculos esenciales de fraternidad (Kaës, 1996). Esto permite consolidar formas de autogestión y protección ante procesos de desvalimiento (Zukerfeld y Zonis, 2003). Esto es indisociable de un cambio en la forma de relacionarse con uno mismo (Castoriadis-Aulagnier, 1975).

Desde esta perspectiva, la importante presencia de la experiencia grupal comunitaria en muchos adultos mayores indica que ellos mismos generan la posibilidad de instaurar procesos nuevos e inéditos (Arias, 2013; Rodríguez, 1995; Fernández et al., 1992; Fernández, 2009). Lo que la sociedad percibe como desamparo, para estos adultos mayores se transforma en una red comunitaria de protección y amparo (Puget y Kaës, 1991).

Al mismo tiempo, la vejez ya no anticipa el signo impostergable de la muerte (Bourdelais, 1993; Ekerdt, 1986), sino una renovación de la promesa de nuevas oportunidades, perspectivas y desafíos (Rosow, 1963; Klein, 2009; 2010; Iacub, 2006). Comienza a armarse una subjetividad con nuevas oportunidades, en la que la figura del anciano decrépito es sustituida por la del agente portador de empoderamiento y resiliencia (Atchley, 1977; Zukerfeld y Zonis, 2003).

No se puede sino insistir en cómo estos adultos mayores demuestran la existencia de una energía y vitalidad emancipatoria asombrosas. ¿Cómo es posible esa magnitud de posibilidad de cambio? La respuesta no es clara y ha de aludirse a múltiples variables sociales, culturales e identitarias (Fonagy, 1999; Kaës, 1996; Butler, 1969). Por nuestra parte, postulamos la hipótesis de un momento generacional de "alta experimentación subjetiva", como elemento de un entramado de factores sociales, culturales, económicos y políticos que es necesario desentrañar.

Se trata de buscar una mayor integración tanto teórica como empírica, que permita comprender el uso de este concepto. La "alta experimentación subjetiva" es una experiencia propia de la vejez que rompe de manera irreversible los estereotipos tradicionales del adulto mayor como alguien en estado de déficit estructural, tanto biológico como psíquico y social. Los achaques, la decadencia física y mental, y el deterioro ya no tienen que ver con este adulto mayor.

Podría decirse que es equiparable a una segunda adolescencia, pero esto no es correcto; más bien, es una segunda o tercera oportunidad vital asociada a la apropiación de la promesa y el porvenir como dispositivos psicosociales basados en la modernidad (Klein, 2006). Lamentablemente, el desarrollo de estos puntos rebasa por mucho el horizonte de este trabajo.

También es pertinente preguntarse si el consumismo que estos "viejos de ahora" adoptaron cuando eran los "jóvenes de ayer" no los está llevando de una u otra manera a tener una actitud rupturista. Creemos que esta hipótesis no merece ser descartada sin antes realizar un estudio especial, que integre en una perspectiva interdisciplinaria el psicoanálisis, la antropología social y la sociología, entre otras disciplinas, lo que también escapa a los objetivos de este trabajo. No obstante, pensamos que es un punto imprescindible, en el que debe profundizarse. D 


\section{Bibliografía}

Arias, Claudia, 2013, "Aportes del apoyo social en el delineamiento de políticas públicas para las personas mayores", en Verónica Montes de Oca (coord.), Envejecimiento en América Latina y el Caribe. Enfoques en investigación y docencia de la Red Latinoamericana de Investigación en Envejecimiento, Universidad Nacional Autónoma de México-Instituto de Investigaciones Sociales, México, pp. 425-452.

Ariès, Philippe y George Duby (orgs.), 1990, Historia de la vida privada, t. 9: La vida privada en el siglo xx, Taurus, Buenos Aires. Atchley, Richard, 1977, The Social Forces in Later Life. An Introduction to Social Gerontology, Wadsworth, Belmont. Aulagnier, Piera, 1991, "Construir(se) un pasado”, en Psicoanálisis, vol. 13, núm. 3, pp. 54-66.

Barros, Regina Duarte de y Adriana Miranda de Castro, 2002, "Terceira idade: o discurso dos experts e a produção do 'novo velho'”, en Estudos Interdisciplinares sobre o Envelhecimento, vol. 4, pp. 113-124.

Bourdelais, Patrice, 1993, L'âge de la vieillesse. Histoire du vieillissement de la population, Odile Jacob, París.

Butler, Robert, 1969, "Age-ism, Another Form of Bigotry", en The Gerontologist, vol. 9, núm. 4, pp. 243-246.

Camarena Córdova, Rosa María, 2005, Población, desarrollo social y grupos vulnerables, Universidad Nacional Autónoma de México, México. Castoriadis-Aulagnier, Piera, 1975, La violencia de la interpretación. Del pictograma al enunciado, Amorrortu, Buenos Aires.

Cole, Thomas, 1997, The Journey of Life, Cambridge University Press, Cambridge.

Comisión Nacional de Protección Social en Salud, s. f., "Información general del Sistema Nacional de Protección Social en Salud”. Disponible en línea: <http://www.salud.gob.mx/transparencia/inform_adicional/InfoGralSP.pdf>.

Consejo Nacional de Evaluación de la Política Social (Coneval), 2012, "Medición de la pobreza”. Disponible en línea: <http://www.coneval.gob. mx/medicion/Paginas/Medici\%C3\%B3n/Pobreza\%202012/Pobreza-2012.aspx>.

Consejo Nacional de Población (Conapo), 2013, La situación demográfica de México 2013, Consejo Nacional de Población, México. Disponible en línea: <http://www.conapo.gob.mx/work/models/CONAPO/Resource/2468/2/images/SDM_2013.pdf>.

—_, 2014, Proyecciones de la población 2010-2050, Consejo Nacional de Población, México. Disponible en línea: <https://www.gob.mx/ conapo/acciones-y-programas/proyecciones-de-la-poblacion-2010-2050>.

Cumming, Elaine y William Henry, 1961, Growing Old, the Process of Disengagement, Basic Books, Nueva York.

Czernikowski, Esther (comp.), 2003, Entre hermanos. Sentido y efectos del vínculo fraterno, Lugar Editorial, Buenos Aires.

Ekerdt, David, 1986, "The Busy Ethic, Moral Continuity between Work and Retirement”, en The Gerontologist, vol. 26, núm. 3, pp. $239-244$.

Fernández Ballesteros, Rocío, 2009, “Evaluación en psicogerontología”, en Rocío Fernández Ballesteros (ed.), Psicología de la vejez. Una psicogerontología aplicada, Pirámide, Madrid, pp. 35-96.

Fernández Ballesteros, Rocío, María Izal Fernández de Trocóniz, Ignacio Montorio, José Luis González Sánchez y Purificación Díaz Veiga, 1992, Evaluación e intervención psicológica en la vejez, Martínez Roca, Barcelona.

Fonagy, Peter, 1999, "Persistencias transgeneracionales del apego: una nueva teoría”, en Aperturas Psicoanalíticas, núm. 3. Disponible en línea: <http://www.aperturas.org/articulos.php?id=0000086\&a=Persistencias-transgeneracionales-del-apego-una-nueva-teoria>.

Foucault, Michael, 1984, "Deux essais sur el sujet et le pouvoir", en Hubert Dreyfus y Paul Rabinow (coords.), Michel Foucault, un parcours philosophique au-delà de l'objectivité et de la subjectivité, Gallimard, París, pp. 201-334.

—_, 2004a, "A ética de cuidado de si como prática da libertade”, en Michel Foucault, Ética, sexualidade, política, Forense Universitária (Ditos \& Escritos V), Río de Janeiro, pp. 264-287.

—_, 2004b, "A tecnología política de los indivíduos", en Michel Foucault, Ética, sexualidade, política, Forense Universitária (Ditos \& Escritos V), Río de Janeiro pp. 301-318.

Giddens, Anthony, 1997a, Modernidad e identidad del yo, Península, Madrid.

_ ción y estética en el orden social moderno, Alianza, Madrid, pp. 145-156.

, 1999, Consecuencias de la modernidad, Alianza, Madrid.

, 2006, La constitución de la sociedad, Amorrortu, Buenos Aires.

Habermas, Jurgen, 2008, "La modernidad, un proyecto incompleto", en Hal Foster (comp.), La posmodernidad, Kairós, Barcelona, pp. 35-43.

Ham Chande, Roberto, 1999, "Conceptos y significados del envejecimiento en las políticas de población”, en El envejecimiento demográfico de México. Retos y perspectivas, Consejo Nacional de Población, México, pp. 41-54.

—_, 2003, El envejecimiento en México. El siguiente reto de la transición demográfica, Miguel Ángel Porrúa/El Colegio de la Frontera Norte, México.

lacub, Ricardo, 2006, Erótica y vejez. Perspectivas de Occidente, Paidós, Buenos Aires.

Instituto Nacional de Estadística y Geografía (INEGI), 2011a, "Diseño conceptual”, en Encuesta Nacional sobre la Dinámica de las Relaciones en los Hogares 2011. Disponible en línea: <http://www.beta.inegi.org.mx/proyectos/enchogares/especiales/endireh/2011/default.html>. 
_ 2011b, Censo de población y vivienda 2010, Instituto Nacional de Estadística y Geografía, México. Disponible en línea: <http://www. beta.inegi.org.mx/proyectos/ccpv/2010/>.

__ 2014, Mujeres y hombres en México 2013, Instituto Nacional de Estadística y Geografía, México. Disponible en línea: <http://internet. contenidos.inegi.org.mx/contenidos/Productos/prod_serv/contenidos/espanol/bvinegi/productos/integracion/sociodemografico/ mujeresyhombres/2013/702825058364.pdf>.

Kaës, René, 1996, Trasmisión de la vida psíquica entre generaciones, Amorrortu, Buenos Aires.

Klein, Alejandro, 2002, Imágenes del adolescente desde el psicoanálisis y el imaginario social. Condiciones de surgimiento de la adolescencia desde la modernidad keynesiana y el disciplinamiento adolescentizante desde la posmodernidad, Psicolibros, Montevideo.

__ 2003, Escritos psicoanalíticos sobre psicoterapia, adolescencia y grupo, Psicolibros/Waslala, Montevideo.

, 2004, Adolescencia, un puzzle sin modelo para armar, Psicolibros/Waslala, Montevideo.

__ 2006, Adolescentes sin adolescencia, Reflexiones en torno a la construcción de subjetividad adolescente bajo el contexto neoliberal, Psicolibros/Universitario, Montevideo.

—_ 2009, "Neoliberalismo-neoevangelismo-cambios socio-demográficos. Posibles marcos epistemológicos frente a algunos desafíos actuales en el campo de las ciencias sociales (Ios paradigmas ambiguos)", en Acciones e Investigaciones Sociales, núm. 27, pp. 69-109.

__, 2010, "Nuevas formas de relacionamiento abuelos-nietos adolescentes desde los cambios demográficos-sociales actuales", en Psicología, núm. 18, vol. 1, pp. 1-25.

- 2013, Subjetividad, familias y lazo social. Procesos psicosociales emergentes, Ediciones Manantial, Buenos Aires.

__, 2016, "Las políticas de salud mental en México, para niños, adultos y ancianos: mucho por hacer, mucho más por reflexionar”, en 0 Social em Questao, año 19, núm. 36, pp. 89-104.

Klein, Alejandro y Marcela Ávila-Eggleton, 2015, "Ciudadanización y desciudadanización de los adultos mayores. El proceso electoral de 2012”, en Sociológica, año 30, núm. 86, pp. 131-166.

Mancinas Espinoza, Sandra y Sagrario Garay Villegas, 2013, “Familia, envejecimiento y políticas sociales”, en Verónica Montes de Oca (coord.), Envejecimiento en América Latina y el Caribe. Enfoques en investigación y docencia de la Red Latinoamericana de Investigación en Envejecimiento, Universidad Nacional Autónoma de México-Instituto de Investigaciones Sociales, México.

Neugarten, Bernice, 1999, Los significados de la edad, Herder, Barcelona.

Neugarten, Bernice y Karol Weinstein, 1964, "The Changing American Grandparents", en Journal of Marriage and Family, vol. 26, núm. 2, pp. 199-204.

Puget, Janine y René Kaës (comps.), 1991, Violencia de Estado y psicoanálisis, Centro Editor de América Latina, Buenos Aires.

Rabell Romero, Cecilia y Sandra Murillo, 2013, “Apoyos recibidos por personas de la tercera edad en México”, en Verónica Montes de Oca (coord.), Envejecimiento en América Latina y el Caribe. Enfoques en investigación y docencia de la Red Latinoamericana de Investigación en Envejecimiento, Universidad Nacional Autónoma de México-Instituto de Investigaciones Sociales, México, pp. $301-332$.

Rodríguez Rodríguez, Pilar, 1995, Residencias para personas mayores, Médica Panamericana, Barcelona.

Rosow, Irving, 1963, Social Integration of the Aged, Free Press, Nueva York.

Secretaría de Salud, 2005, Sistema de Protección Social en Salud. Elementos conceptuales, financieros y operativos, Secretaría de Salud, México. Disponible en línea: <http://www.salud.gob.mx/unidades/cdi/documentos/DOCSAL7723.pdf>

Sistema Nacional de Información Estadística y Geográfica (SNIEG), 2017, "Catálogo nacional de indicadores". Disponible en línea: <http:// www3.inegi.org.mx/sistemas/cni/sereferencia.aspx>.

Tuirán, Rodolfo, 1999, "Desafíos del envejecimiento demográfico en México”, en El envejecimiento demográfico de México. Retos y perspectivas, Consejo Nacional de Población, México, pp. 15-22.

Villagómez Ornelas, Paloma, 2009, "El envejecimiento demográfico en México, niveles, tendencias y reflexiones en torno a la población de adultos mayores”, México, inédito.

Zukerfeld, Rubén y Raquel Zonis Zukerfeld, 2003, "Procesos terciarios”, en Aperturas Psicoanalíticas, núm. 14. Disponible en línea: <http:// www.aperturas.org/articulos.php?id=0000253\&a=Procesos-terciarios>.

\section{Entrevistas}

Enrique, León, Guanajuato, de julio a noviembre de 2016.

José, León, Guanajuato, de julio a noviembre de 2016.

Juan, León, Guanajuato, de julio a noviembre de 2016. 